\title{
Thoroughly enthralling thulium
}

\author{
Named after a mysterious place, thulium - one of the rarest rare earths - has some exotic chemistry in \\ store for us, says Polly Arnold.
}

T hulium — isolated by a Swedish chemist like so many of the other rare earths - is named after a mysterious place in the far northern corners of Europe. The Thule of medieval geography (and its variations such as Tile, as seen in the 1539 map by cartographer Olaus Magnus, pictured) has since been attributed to a variety of places including Iceland, islands north of Scotland, and Scandinavia. It is the latter that Per Teodor Cleve referred to when he proposed a name for element 69, which he identified in 1879 while studying the mineral 'erbia' from the Swedish town of Ytterby, working on isolating different rare-earth trications from each other - a notoriously challenging endeavour, given their very similar behaviours.

Thulium is relatively expensive and has only found commercial application in lowvolume uses in the medical field as a dopant to the yttrium aluminium garnet (YAG; $\mathrm{Y}_{3} \mathrm{Al}_{5} \mathrm{O}_{12}$ ) used in surgical lasers, and its radioactive isotope ${ }^{170} \mathrm{Tm}$ serves as a source of X-rays for portable devices. Its sharp inter- $4 f$-orbital electronic transitions are also exploited in anti-counterfeiting inks in Euro currency banknotes, whose blue fluorescence under UV light arises from $\mathrm{Tm}^{3+}$ ions.

Rare-earth chemistry in solution mostly occurs in the +3 oxidation state. Nevertheless, divalent rare-earth halides $\left(\mathrm{REX}_{2}\right.$, with $\mathrm{RE}$ a rare-earth element, $\mathrm{X}$ a halide $\mathrm{F}-\mathrm{I}$ ) are accessible for europium, ytterbium and samarium, which approach or achieve a full- or half-full $f$-shell in this oxidation state. Indeed, samarium diiodide and its solvates (which help tune its solubility and reducing power) have been used for around fifty years now by organic chemists for controlled oneelectron reduction reactions of a range of functional groups, including carbonyl, alkyl halide and nitro groups ${ }^{1}$.

Although textbooks stipulate the absence of the +2 oxidation state for the other rare earths in solution, research chemists know of three others - neodymium(II), dysprosium(II)

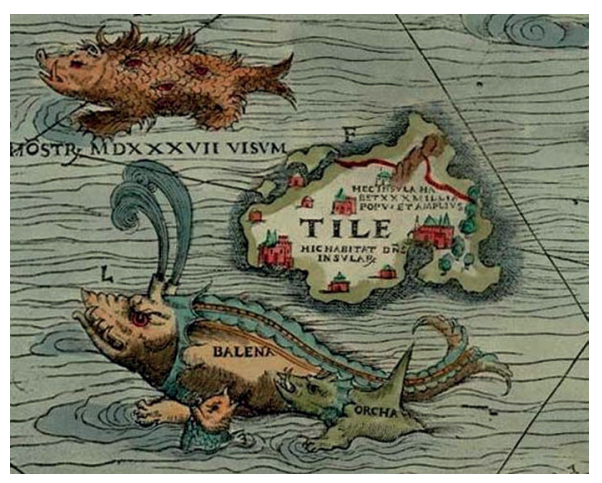

and thulium(II). Although they are extremely difficult to reduce, and can only be isolated with the right ligands, they can be accessed by comproportionation $\left(2 \mathrm{REX}_{3}+\mathrm{RE}=3 \mathrm{REX}_{2}\right)$, or through $\mathrm{REX}_{3}$ reduction by a very strongly reducing metal such as potassium.

In 1997, with the report that $\mathrm{TmI}_{2}$ could be dissolved and solvated in the ether solvents dimethoxyethane (DME) and tetrahydrofuran $(\mathrm{THF})^{2}$, Bochkarev made the breakthrough that launched the reactivity of compounds of all of the rare earths(II) in solution. Until then, formally zero-oxidation-state complexes (with strong colours arising from metal-ligand charge transfers ${ }^{3}$ ) made using metal vapours had been the only known low-oxidation-state complexes of these 'non-reducible' rare earths.

As one of the rarest rare earths, thulium will not be replacing samarium as organic chemists' reductant of choice any time soon due to its high cost ${ }^{4}$. Yet its potential for exotic new chemistry is enormous. Using organometallic ligands and techniques, we can make compounds that do not follow the well-established rules of the $d$-block metals. Studying their fundamental electronic structures and bonding subtleties can then help us gain a better understanding of - and in turn a better ability to manipulate - the heavy, relativistic and often radioactive metals of the $f$-block metals, whose reactivities are critical to renewable energy, magnet technologies and nuclear waste management.

The capacity for ligands to tune organometallic species is phenomenal - ligand choice for example can shift the formal potential of a particular metal redox couple by as much as $1.5 \mathrm{eV}$. The first organometallic thulium(II) complex reported was isolated by replacement of the iodides of $\mathrm{TmI}_{2}(\mathrm{THF})_{3}$ by a silyl-functionalized cyclopentadienyl anion, which is well-known for its capacity to stabilize formally low-oxidation-state metal cations through electron-density acceptance from the metal (back-donation). At low temperatures, dark purple crystals of the THF solvate were grown and characterized. These colours are typical of rare-earth(II) systems; at room temperature these slowly react to deoxygenate the solvents, returning to the pale-yellow colours of $5 d^{0}-\mathrm{RE}$ (III) ions.

The high reactivity of these complexes means that no suitable method to record the potential of the metal's redox couple in solution has yet been developed. However, pleasingly, there has been a resurgence in the development of new ligands that can shift these redox couples by manipulating geometries and orbital overlap ${ }^{5-8}$, and in the search for other metals in the f-block including even the highly radioactive transuranic elements ${ }^{9}$ - that can exhibit new, low formal oxidation states. New data suggest different $d / f$ electron configurations are now achievable $^{10}$; future undergraduates may be disappointed to have to learn ligand-field theory for the $f$-block as well as the $d$-block.

POLLY ARNOLD is at the EaStCHEM School of Chemistry, University of Edinburgh, The King's Buildings, Edinburgh EH9 3FJ, UK. e-mail:Polly.Arnold@ed.ac.uk Twitter: @ProfArno

\footnotetext{
References

1. Strekopytov, S. Nat. Chem. 8, 816-816 (2016).

2. Bochkarev, M. N. et al. Angew. Chem. Int. Ed. 36, 133-135 (1997).

3. Cloke, F. G. N. Chem. Soc. Rev. 22, 17-24 (1993).

4. Kagan, H. B. Tetrahedron 59, 10351-10372 (2003).

5. La Pierre, H. S., Scheurer, A., Heinemann, F. W., Hieringer, W. \& Meyer, K. Angew. Chem. Int. Ed. 53, 7158-7162 (2014).

6. Dutkiewicz, M. S. et al. Nat. Chem. 8, 797-802 (2016).

7. Anderson, N. H. et al. Nat. Chem. 6, 919-926 (2014).

8. Goodwin, C. A. P. et al. Inorg. Chem. 55, 10057-10067 (2016).

9. Arnold, P. L., Dutkiewicz, M. S. \& Walter, O. Chem. Rev. 117, 11460-11475 (2017).

10. Fieser, M. E. et al. Chem. Sci. 8, 6076-6091 (2017).
}

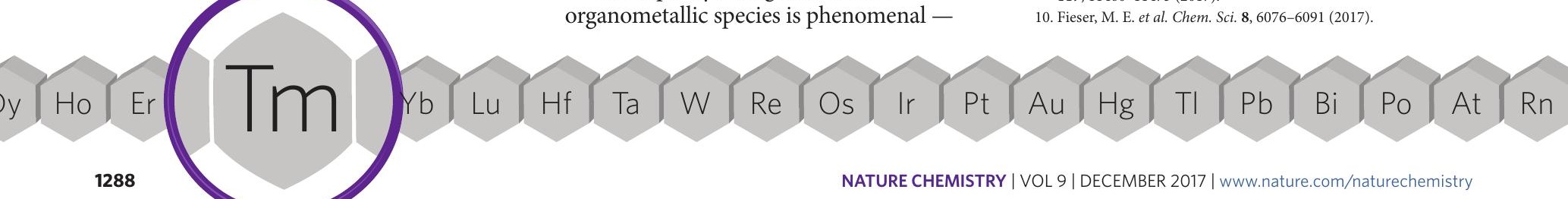

